\title{
Downregulation of cytokeratin 18 is associated with paclitaxel-resistance and tumor aggressiveness in prostate cancer
}

\author{
BO YIN ${ }^{1}$, MO ZHANG $^{1}$, YU ZENG $^{2,3^{*}}$, YOUQIANG LI ${ }^{3}, \mathrm{CHAO} \mathrm{ZHANG}^{1}$ and YONGSHENG SONG ${ }^{1 *}$ \\ ${ }^{1}$ Department of Urology, Shengjing Hospital of China Medical University, Shenyang, Liaoning 110004; \\ ${ }^{2}$ Department of Urology, The First Hospital of China Medical University, Shenyang, Liaoning 110001, P.R. China; \\ ${ }^{3}$ James Buchanan Brady Urological Institute, The Johns Hopkins University School of Medicine, Baltimore, MD 21087, USA
}

Received December 21, 2015; Accepted January 30, 2016

DOI: $10.3892 /$ ijo.2016.3396

\begin{abstract}
Paclitaxel frequently serves as the first-line chemotherapeutic agent for castration-resistant prostate cancer (PCa) patients. However, acquired paclitaxel-resistance almost always occurs after initial responses, and the mechanisms by which this occurs remain largely unknown. The goal of the present study was to identify differentially expressed protein(s) associated with paclitaxel-resistance and further explore the potential mechanisms involved in drug resistance. By comparing the nuclear matrix protein (NMP) patterns of DU145-TxR cells, the previously established stable paclitaxelresistant PCa cells, with that of the parental DU145 cells using two-dimensional electrophoresis, we found that cytokeratin 18 (CK18) is downregulated in DU145-TxR cells. The downregulation of CK18 in DU145-TxR cells at mRNA, NMP and total cellular protein levels was validated by real-time RT-PCR, immunoblotting and immunofluorescence, indicating that the downregulation of CK18 was a global effect in DU145-TxR cells due to paclitaxel-resistance. Furthermore, in vivo assay of xenograft transplantation confirmed the higher tumorigenicity of DU145-TxR cells, suggesting that these paclitaxel-resistant PCa cells possessed potent cancer stem cell (CSC)-like properties and eventually developed paclitaxel-resistance. Moreover, we determined by immunohistochemistry that CK18 expression in PCa tissues was inversely correlated with tumor grade in a statistically significant fashion, indicating a potential association of the downregulation of CK18 with tumor aggressiveness. Therefore, further study to define the potential role of CK18 may lead to novel therapy strategies as well as clinically useful biomarker for PCa patients.
\end{abstract}

Correspondence to: Dr Yongsheng Song, Department of Urology, Shengjing Hospital of China Medical University, 36 Sanhao Street, Shenyang, Liaoning 110004, P.R. China

E-mail: yinbowzf@163.com

*Contributed equally

Key words: prostate cancer, paclitaxel-resistance, cytokeratin 18, cancer stem cell

\section{Introduction}

Prostate cancer (PCa) is the most commonly diagnosed cancer and the second leading cause of cancer-related death in American men (1). Androgen deprivation therapy (ADT) is currently the standard therapeutic modality for advanced, metastatic PCa. ADT initially induces an antitumor response in more than $90 \%$ of patients. However, the efficacy of androgen withdrawal is temporary, and tumors in the majority of these patients eventually relapse and evolve into an androgeninsensitive stage, known as castration-resistant prostate cancer (CRPC), which is commonly fatal (2). Chemotherapy plays an increasingly important role in the management of CRPC patients. Recently, taxanes (paclitaxel or docetaxel) in combination with various adjuvants, have been shown to induce effective antitumor responses and improve the overall survival of CRPC patients $(3,4)$. Originating from the bark of a yew tree, paclitaxel acts as an antitumor agent that promotes apoptosis in cancer cells by stabilizing the microtubule cytoskeleton (5). Paclitaxel currently serves as the first-line chemotherapeutic agent for CRPC patients. However, acquired paclitaxel-resistance almost always occurs after initial responses, which is essentially incurable.

One of the hallmarks of cancer cell adaption to the microenvironmental stresses, such as chemotherapeutics, heat and radiation, is alterations in the nuclear architecture (6-8). In concordance with these changes are alterations in nuclear matrix proteins (NMPs) which comprise the structural elements of the nucleus and likely act as a signature for tumorigenesis. The NMPs are a well-structured and dynamic network of filaments that functions in the nucleus similarly to that of microtubules and tubulin in the cytoplasm (9). Some specific NMP patterns associated with cancers, including bladder, prostate and colon cancers have been identified. Assessment of these NMP changes resulted in further elucidation of functional implications as well as the identification of biomarkers (6,7,10-13).

To date, the mechanisms of acquired paclitaxel-resistance remain largely unknown. Presently, the main identified mechanisms relate to the expression of $\beta$-tubulin isoforms/ mutations and the activation of drug efflux pumps (14). However, in spite of these advances, treatment of paclitaxelresistant PCa patients remains a critical clinical challenge. 
We have previously established a stable paclitaxel-resistant DU145-TxR cell line from the androgen-independent DU145 cell line, which mimics to a certain extent the progression of paclitaxel-resistance in PCa patients $(8,15)$. In the present study, we aimed to identify differentially expressed protein(s) associated with paclitaxel-resistance by comparing the NMP patterns of DU145-TxR cells with that of DU145 cells and further explore the potential mechanisms involved in the drug resistance, which may help develop novel therapeutic strategies as well as clinically useful biomarker(s) for $\mathrm{PCa}$ patients.

\section{Materials and methods}

Cell lines and cell culture. The CRPC cell line DU145 was purchased from the American Type Culture Collection (ATCC; Rockville, MD, USA). DU145 cells were cultured in Dulbecco's modified Eagle's medium (DMEM; Invitrogen, Carlsbad, CA, USA) supplemented with $10 \%$ fetal bovine serum (FBS; Gibco, Shanghai, China) at $37^{\circ} \mathrm{C}$ in incubator with humidified air and $5 \%$ carbon dioxide. The stable paclitaxel-resistant DU145-TxR cells were generated by culturing DU145 cells with stepwise increasing concentrations of paclitaxel $(8,15)$. The initial culture was at $10 \mathrm{nM}$ paclitaxel (Sigma-Aldrich, St. Louis, MO, USA) for 2 days. Then the medium was changed to fresh one without paclitaxel until the cells grew well. Subsequently, the surviving DU145 cells were cultured with paclitaxel in a dose-escalation manner using 48-h exposure to establish stable paclitaxel-resistant DU145-TxR cells. The process of acquired paclitaxel-resistance took 10 months. The DU145-TxR cells were routinely cultured in normal DMEM medium as described above supplemented with $10 \mathrm{nM}$ paclitaxel to maintain their drug-resistant phenotypes. Prior to each experiment, these cells were grown for a minimum of two passages in normal DMEM medium.

Human prostate cancer tissue samples. Formalin-fixed paraffin-embedded human primary $(n=38)$ and metastatic $(n=22)$ PCa tissue samples were obtained from patients undergoing transrectal ultrasound-guided biopsy, from 2012 to 2015, at Shengjing Hospital of China Medical University. This study protocol was approved by the Institutional Review Board of Shengjing Hospital of China Medical University. Informed consent was obtained from each patient.

Cell viability assay. Cells $(2,500)$ per well were seeded in 96-well plates. After culturing for $24 \mathrm{~h}$, cells were treated with the indicated concentrations of paclitaxel and cultured for an additional $48 \mathrm{~h}$. At the end of the culture period, cell proliferation reagent WST-1 (4-[3-(4-iodophenyl)-2-(4nitrophenyl)-2H-5-tetrazolio]-1,3-benzene disulfonate) was added to each well, as specified by the supplier (Roche, Nutley, NJ, USA). After 3-h incubation, WST-1 absorbance at $450 \mathrm{~nm}$ was measured.

Isolation of nuclear matrix proteins (NMPs), two-dimensional (2D) gel electrophoresis and mass spectrometry. NMP isolation and high resolution, two-dimensional (2D) electrophoresis was performed as previously described (6,7,10-13). Multiple gels were run for each sample and at least three samples for each cell line were run at different times. The comparison of NMP patterns was done by image analysis software together with visual inspection (6,7). Protein spots significantly differentially expressed were excised for mass spectrometry analysis. Mass spectrometry analysis was performed at the Mass Spectrometry/Proteomics Core Facility, The Johns Hopkins University School of Medicine $(6,7,16)$.

Real-time reverse transcription-PCR. Total RNA was isolated and treated with DNase I (Invitrogen) following the supplier's protocol (Qiangen, Valencia, CA, USA). cDNA was synthesized using the iScript cDNA synthesis kit (Bio-Rad Laboratories, Hercules, CA, USA). Real-time PCR was done in triplicate on an iCycler iQ Multicolor Real-time PCR detection system (Bio-Rad Laboratories). Target gene expression was related to TATA box binding protein (TBP) for normalization. The sequences of primers used for PCR analyses are as follows: CK18, forward, 5'-TAGATGCCCCCAAATCT CAG-3' and reverse, 5'-CACTGTGGTGCTCTCCTCAA-3'; TBP, forward, 5'-GAATATAATCCCAAGCGGTTTG-3' and reverse, 5'-ACTTCACATCACAGCTCCCC-3'.

Immunoblotting. Briefly, protein $(25 \mu \mathrm{g})$ was separated on a 4-15\% SDS-PAGE and transferred onto PVD filters (Millipore, Bedford, MA, USA). Membranes were incubated with primary antibodies overnight at $4^{\circ} \mathrm{C}$ followed by horseradish peroxidase-conjugated secondary antibodies for $2 \mathrm{~h}$ at room temperature, and developed with the SuperSignal West Dura Extended Duration Substrate kit (Pierce, Rockford, IL, USA) (17). Mouse monoclonal anti-CK18, rabbit polyclonal anti-actin and mouse monoclonal anti-lamin $\mathrm{A} / \mathrm{C}$ antibodies were purchased from Santa Cruz Biotechnology (Santa Cruz, CA, USA). Secondary antibodies including sheep anti-mouse antibody linked with horseradish peroxidase and donkey anti-rabbit antibody linked with horseradish peroxidase were purchased from GE Healthcare (Little Chalfont, UK). Lamin $\mathrm{A} / \mathrm{C}$ was used as a loading control for NMPs, and actin for total cellular protein.

Immunofluorescence. Double immunofluorescence was applied simultaneously to detect the expression of CK18 and actin. Briefly, cells were fixed with $4 \%$ paraformaldehyde in PBS (Affymetrix Inc., Santa Clara, CA, USA) for $15 \mathrm{~min}$ at room temperature, washed three times with PBS, and blocked with $1 \%$ bovine serum albumin (BSA; Thermo Fisher Scientific, Waltham, MA, USA) in PBST (0.3\% Triton X-100 in PBS) for $1 \mathrm{~h}$. Slides were then incubated with the mixture of two primary antibodies including anti-CK18 antibody and anti-actin antibody in $1 \% \mathrm{BSA}$ in PBST overnight at $4^{\circ} \mathrm{C}$. The mixture of two secondary antibodies including Alexa Fluor555 labeled goat anti-mouse (Molecular Probes, Eugene, OR, USA) and Alexa Fluor 488 labeled goat anti-rabbit (Molecular Probes) antibodies in 1\% BSA in PBST was applied and incubated for $2 \mathrm{~h}$ at room temperature in the dark. The cells were also washed three times with PBS and mounted with ProLong Gold antifade reagent (Invitrogen) with 4',6-diamidino-2-phenylindole (DAPI) to detect the nuclei. Slides were observed with a Nikon Eclipse TE2000E using the GFP-BP Filter (Ex 460-500, DM 5005, DA: 510-560). 
Xenograft transplantation. All mouse procedures were carried out in accordance with the institutional protocol guidelines at Shengjing Hospital of China Medical University. Xenograft experiments were performed with 6- to 8-week-old female nonobese diabetic/severe combined immunodeficient (NOD/ SCID) mice provided by the Model Animal Research Center of China Medical University, Shenyang, China. DU145-TxR and DU145 cells were resuspended in $50 \mu$ l PBS in quantities ranging from $10^{3}$ to $10^{5}$ cells. Cells were then mixed with $50 \mu 1$ Matrigel (BD Biosciences, San Jose, CA, USA) and injected into the subcutaneous space of the back of NOD/SCID mice (5 mice per group). Tumor growth was monitored weekly and quantified by caliper measurements. Tumor volume was calculated using the formula: $V=\left(a^{2} \times b\right) / 2$, where $a$ and $b$ are the minimal and maximal diameter in millimeters, respectively.

Immunohistochemistry. Immunohistochemical staining was conducted using formalin-fixed paraffin-embedded tissue samples (18). Briefly, tissue sections were deparaffinized, rehydrated and microwaved for antigen retrieval. Subsequently, the sections were incubated with mouse anti-CK18 monoclonal antibody (Santa Cruz Biotechnology) at 1:150 overnight at $4^{\circ} \mathrm{C}$, followed by detection using PowerVision Two-Step histostaining reagent (Beijing Zhongshan Golden Bridge Biotechnology Co., Ltd., Beijing, China).

The results of immunohistochemical staining were scored by two pathologists, who were blinded to clinical data. CK18 expression was scored using a semi-quantitative method by evaluating the number of positive tumor cells over the total number of tumor cells. CK18 staining was scored according to the intensity and proportion of positive cells as follows: -, no positive staining cells; + , weak intensity with $<25 \%$ positive staining cells; ++ , moderate intensity with $26-50 \%$ positive staining cells; and +++ , strong intensity with $>50 \%$ positive staining cells.

Statistical analysis. Statistical analysis was done with the SPSS version 16.0 (SPSS, Inc., Chicago, IL, USA). Experimental data are presented as means \pm SD and analyzed by the Student's t-test for determining statistical significance between groups. Pearson's chi-squared test $\left(\chi^{2}\right)$ was performed to compare the correlation of clinicopathological characteristics with CK18 expression. $\mathrm{P}<0.05$ was considered statistically significant.

\section{Results}

Confirmation of paclitaxel-resistance in DU145-TxR cells. We confirmed the paclitaxel-resistance of the DU145-TxR cells as compared to their parental DU145 cells by evaluating cell viability at different concentrations of paclitaxel (Fig. 1). DU145 and DU145-TxR cells were treated with increasing concentrations of paclitaxel for $48 \mathrm{~h}$. At the end of the culture period, cell viability was determined by WST-1 assay. The $\mathrm{IC}_{50}$ of the DU145 cells was $4.75 \mathrm{nM}$ and the $\mathrm{IC}_{50}$ of the DU145-TxR cells increased dramatically to $>100 \mathrm{nM}$ (Table I). The DU145-TxR cells are at least 20-fold more paclitaxel resistant than the parental DU145 cells.

Cytokeratin 18 (CK18) is downregulated in DU145-TxR cells. To identify differentially expressed protein(s) associated with

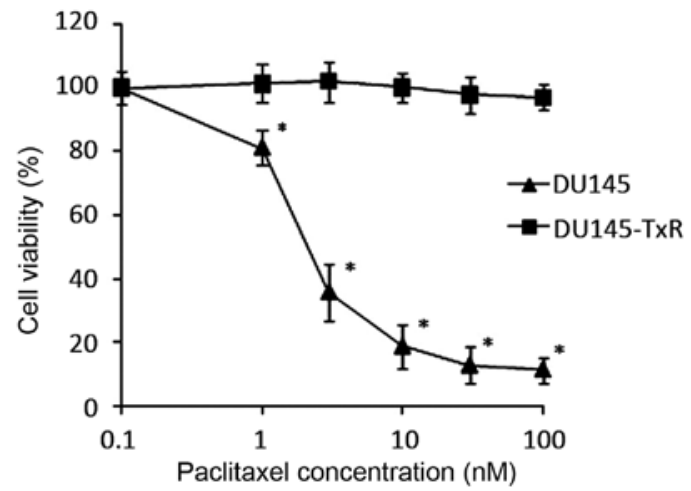

Figure 1. Confirmation of paclitaxel-resistance in DU145-TxR cells. Cell viability of DU145 and DU145-TxR cells treated with increasing concentrations of paclitaxel for $48 \mathrm{~h}$. Cell viability was determined by WST-1 assay. Data are expressed as mean $\pm \mathrm{SD} .{ }^{*} \mathrm{P}<0.05$.

Table I. IC S0 $_{0}$ values of DU145 and DU145-TxR cells.

\begin{tabular}{lccc}
\hline Drug & DU145 & DU145-TxR & Fold change \\
\hline Paclitaxel (nM) & 4.75 & $>100$ & $>20$ \\
\hline
\end{tabular}

paclitaxel-resistance, we investigated the NMP patterns of DU145-TxR cells compared to that of the parental DU145 cells by high-resolution two-dimensional gel electrophoresis. As shown in Fig. 2, our data were similar with our previous results (15). Analyses of the high-resolution two-dimensional gels showed that several protein spots were present in DU145 cells, but significantly downregulated in DU145-TxR cells. Of note, protein spot 1 (Fig. 2A) was reproducibly observed to be downregulated in DU145-TxR cells in comparison with the parental DU145 cells. This spot was excised from the twodimensional gels and analyzed by mass spectrometry, which suggested this protein as cytokeratin 18 (CK18) (Table II).

To validate the identification of CK18 in two-dimensional gels, we further examined the expression of CK18 in DU145 and DU145-TxR cells. Firstly, we determined the mRNA level of CK18 by real-time RT-PCR. As shown in Fig. 2B, we found downregulation of CK18 mRNA in DU145-TxR cells as compared to the parental DU145 cells. Then we determined the protein level of CK18 by immunoblotting. As expected, CK18 protein was significantly downregulated in the NMPs of DU145-TxR cells upon normalization with lamin A/C (Fig. 2C).

In order to understand whether the difference of CK18 expression in NMPs was a result of alterations in protein compartmentalization, we extracted and analyzed the total cellular protein by immunoblotting. These immunoblotting studies demonstrated that CK18 protein was constitutively downregulated in the total cellular protein of DU145-TxR cells in comparison with the parental DU145 cells upon normalization with Actin (Fig. 2D). Considered together, CK18 was downregulated in DU145-TxR cells at both NMP and total cellular protein levels, indicating a global effect rather than a redistribution of CK18 away from the nucleus in the paclitaxelresistant DU145-TxR cells. 

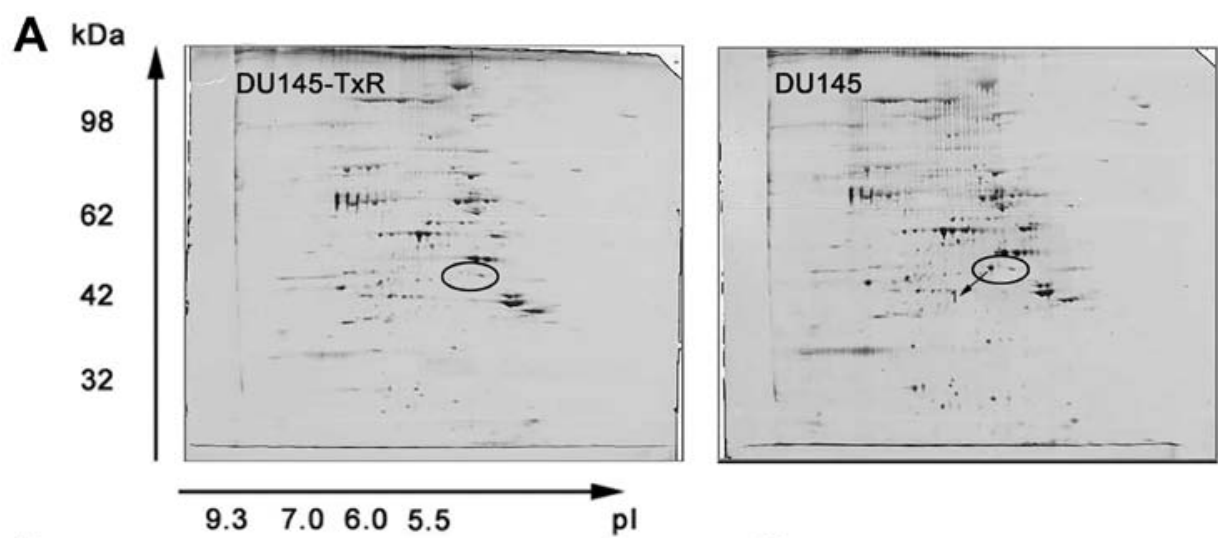

B
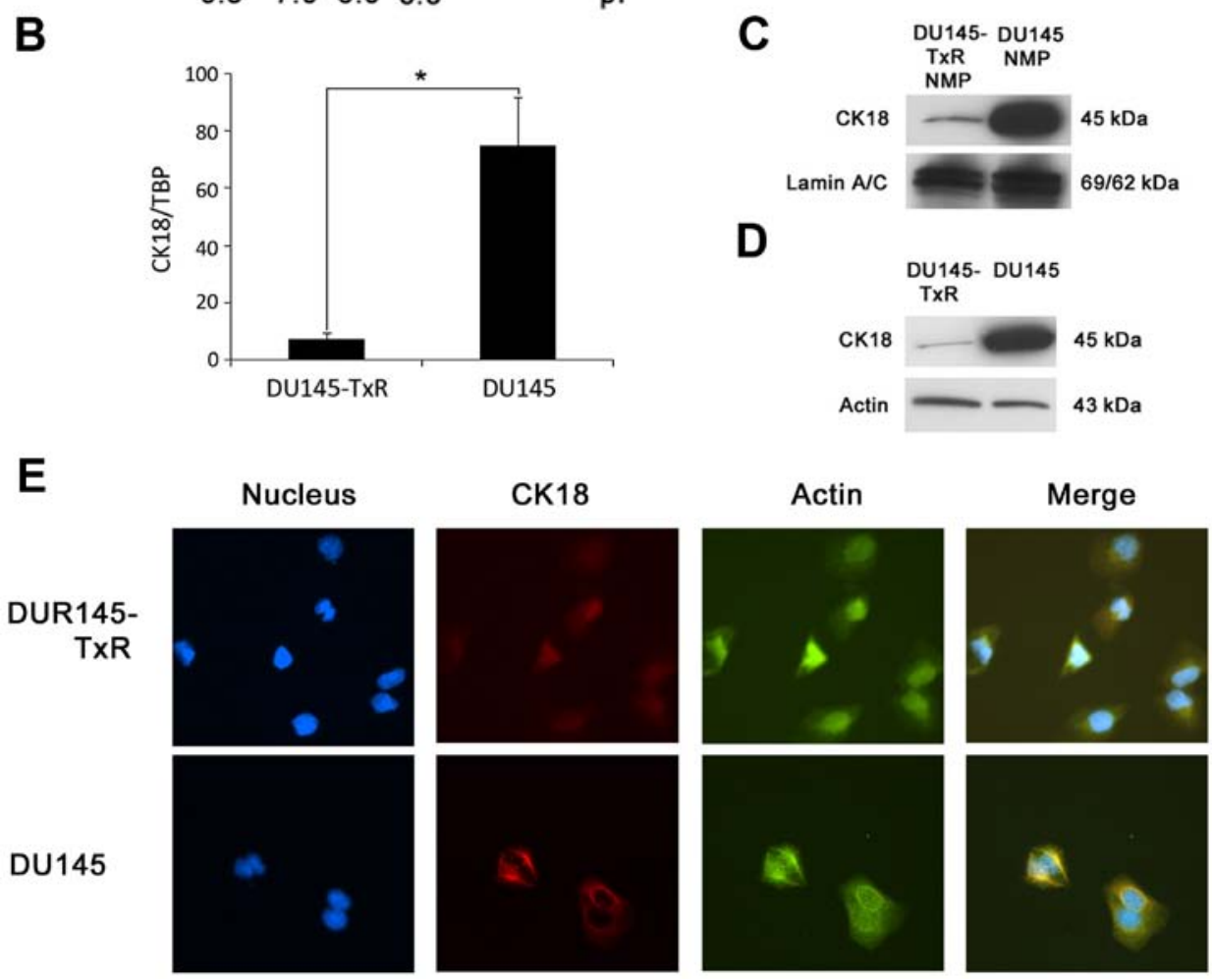

Figure 2. CK18 is downregulated in DU145-TxR cells. (A) Comparison of NMP patterns of DU145-TxR and DU145 cells by two-dimensional gel electrophoresis. Mass spectrometry identified spot 1 as CK18, which was expressed in DU145 but downregulated in DU145-TxR cells. (B) The downregulation of CK18 mRNA in DU145-TxR cells as compared to DU145 cells was validated by real-time RT-PCR. Values are expressed relative to the expression of TBP. Data are mean \pm SD. ${ }^{*} \mathrm{P}<0.05$. (C) The downregulation of CK18 in the NMPs of DU145-TxR cells as compared to DU145 cells was validated by immunoblotting. Lamin $\mathrm{A} / \mathrm{C}$ was used as a loading control. (D) The downregulation of CK18 in the total cellular protein of DU145-TxR cells as compared to DU145 cells was validated by immunoblotting. Actin was used as a loading control. (E) Immunofluorescence analysis of CK18 (red) and actin (green) in DU145-TxR and DU145 cells. DAPI (blue) was used to stain the nuclei (magnification, x200).

Table II. Mass spectrometry analysis of NMP from DU145 cells.

\begin{tabular}{ccccccc}
\hline Protein spot & MW (kDa) & pI & Protein identity & $\begin{array}{c}\text { Accession } \\
\text { number }\end{array}$ & $\begin{array}{c}\text { Peptide sequence } \\
\text { coverage (\%) }\end{array}$ & $\begin{array}{c}\text { No. of (\%) } \\
\text { unique peptides }\end{array}$ \\
\hline 1 & 47 & 5.27 & Cytokeratin 18 (Homo-sapiens) & gil30311 & 44 & 16 \\
\hline
\end{tabular}

Furthermore, immunofluorescence was applied to examine the expression and intracellular location of CK18 in DU145 and DU145-TxR cells. As shown in Fig. 2E, more intense CK18 fluorescence was observed in DU145 cells, whereas only faint CK18 fluorescence was observed in DU145-TxR cells. CK18 appeared to be localized mainly at the cytoskeleton predomi- nantly in the cytoplasm. These results further suggested that the downregulation of CK18 was a global effect in DU145-TxR cells due to paclitaxel-resistance.

DU145-TxR cells possess cancer stem cell-like properties. Some recent studies have shown that cancer stem cells 


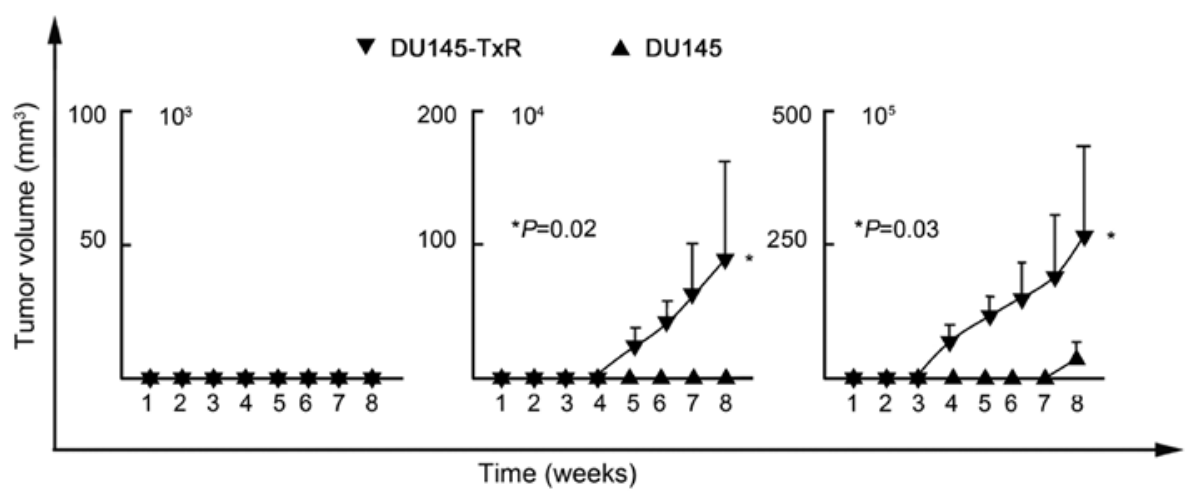

Figure 3. DU145-TxR cells possess cancer stem cell-like properties. Higher tumorigenicity of DU145-TxR cells was validated by in vivo xenograft transplantation. Data are means $\pm \mathrm{SD} ;{ }^{*} \mathrm{P}<0.05$.
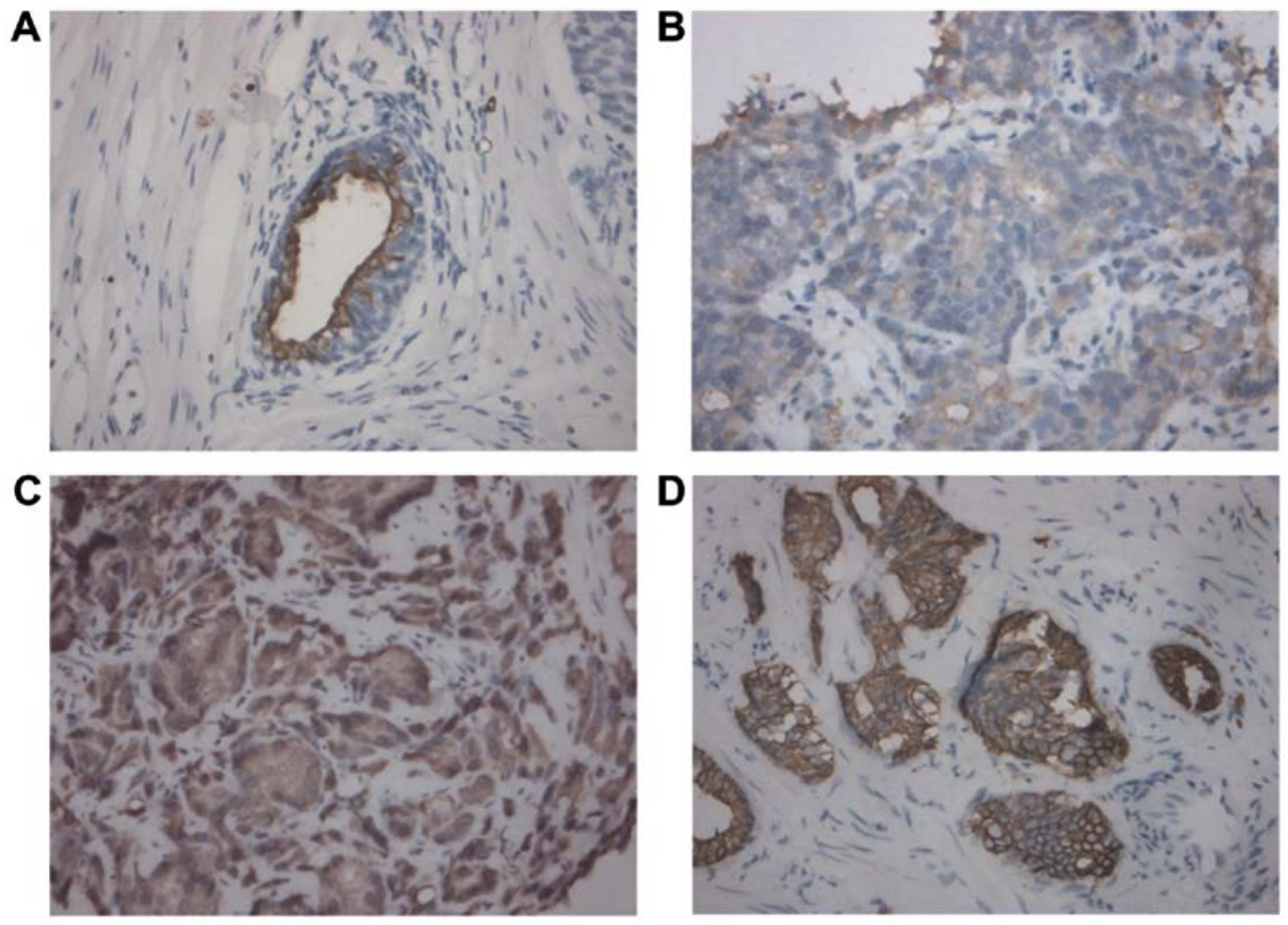

Figure 4. Immunohistochemical staining of CK18 in human PCa tissue samples. Panels refer to representative images (magnification, $\mathrm{x} 400$ ). (A) CK18 expression in PCa with Gleason score 8 (intensity -); (B) CK18 expression in PCa with Gleason score 7 (intensity +); (C) CK18 expression in PCa with Gleason score 6 (intensity ++); (D) CK18 expression in PCa with Gleason score 6 (intensity +++).

Table III. Tumor initiating ability of DU145-TxR and DU145 cells.

\begin{tabular}{lcc}
\hline Cell type & Cell dose & Tumor incidence \\
\hline DU145-TxR & $10^{3}$ & $0 / 5^{\mathrm{a}}$ \\
& $10^{4}$ & $2 / 5$ \\
& $10^{5}$ & $4 / 5$ \\
DU145 & $10^{3}$ & $0 / 5$ \\
& $10^{4}$ & $0 / 5$ \\
& $10^{5}$ & $1 / 5$ \\
\hline
\end{tabular}

${ }^{a}$ The number of mice with a detected tumor; $n=5$.
(CSCs) may preferentially survive exposure to chemotherapy, providing an attractive rationale for relapse following initial tumor shrinkage with standard therapy $(19,20)$. Thus, we further investigated the CSC-like properties of these DU145-TxR cells. Because efficient xenograft transplantation is a major criterion for the validation of CSCs (21), we inoculated serial dilutions of DU145-TxR and DU145 cells into NOD/SCID mice. As shown in Table III and Fig. 3, DU145-TxR cells initiated tumor formation with $10^{4}$ ( 2 of 5 mice) and $10^{5}$ (4 of 5 mice) cells, whereas DU145 cells needed $10^{5}$ ( 1 of 5 mice) to initiate tumor formation. Therefore, DU145-TxR cells have much more efficient tumorigenicity than DU145 cells. These data validated that DU145-TxR cells possessed potent CSC-like properties and eventually developed paclitaxel-resistance. 
Table IV. CK18 expression by IHC correlated with tumor grade of $\mathrm{PCa}$.

\begin{tabular}{lcccc}
\hline & & \multicolumn{2}{c}{ CK18 expression } & \\
\cline { 3 - 4 } $\begin{array}{l}\text { Tumor } \\
\text { grade }\end{array}$ & $\begin{array}{c}\text { Total } \\
\text { number }\end{array}$ & - to + & ++ to +++ & P-value \\
\hline Gleason score & & & & \\
$<7$ & 25 & 10 & 15 & 0.028 \\
$\geq 7$ & 35 & 24 & 11 & \\
Total number & 60 & 34 & 26 & \\
\hline
\end{tabular}

Downregulation of CK18 in prostate cancer tissues is associated with tumor aggressiveness. Immunohistochemistry was performed to investigate the correlation between CK18 expression and clinicopathological characteristics of human PCa tissue samples in terms of tumor stage and grade. As shown in Fig. 4 and Table IV, CK18 protein was predominantly expressed in the cytoplasm of cancer cells and the expression of CK18 was inversely correlated with tumor grade in a statistically significant fashion $(\mathrm{P}=0.028)$ : tissue samples with higher tumor grades (Gleason score $\geq 7$ ) showed gradually decreased immunostaining intensity. We did not detect any significant correlation between CK18 expression and tumor stage ( $\mathrm{P}>0.05$, data not shown). These data suggested a potential association between the downregulation of CK18 and tumor aggressiveness of PCa.

\section{Discussion}

In the present study, we determined that CK18 is downregulated in the paclitaxel-resistant DU145-TxR cells as compared to the parental DU145 cells and is associated with the acquisition of paclitaxel-resistance. CK18 is a member of cytokeratins which are the products of a large gene family of the intermediate filament genes. The family is divided into six types or subclasses based on the sequence characteristics of the genes and their products, of which cytokeratins make up type I (acidic, CK9-CK20) and type II (neutral-basic, CK1-CK8) groups (22). CK18 is the representative of the acidic type I cytokeratins and has been recognized for $>30$ years as an epithelial marker in diagnostic histopathology (23). Furthermore, CK18 is one of the most prevalent and often downregulated cytokeratins in malignant cell lines and many types of carcinomas (24).

Various regulatory changes in cytokeratin expression at the transcriptional and post-transcriptional levels have been described in experimental studies on epithelial tumor cells, challenging the view that cytokeratins are merely marker protein $(25,26)$. Although the recognized function of cytokeratins, in general, has been defined historically as structural because of their interactions with the extracellular matrix and their role in cell-cell contact and adhesion (27), these structurally related proteins also influence protein synthesis and modulate intracellular cytokine signaling cascades (28). Some authors have observed the association of downregulation of CK18 with anticancer drug resistance. Parekh et al (29) reported that the cisplatin-resistant human ovarian 2008/13 cell line contained markedly lower level of CK18 when compared with the sensitive parental cells. Transfection of full-length CK18 cDNA into this cell line increased sensitivity to cisplatin. Liang et al (30) reported that the paclitaxel-resistant human nasal RPMI-2650Tx cell line displayed a decrease in CK18 expression compared with the parental RPMI-2650 cells. Our data also suggested that CK18 is downregulated in the paclitaxel-resistant DU145-TxR cells. We have been investigating the potential role of CK18 in the development of paclitaxel-resistance in these DU145-TxR cells. However, transfection of full-length CK18 cDNA into this cell line did not reverse the paclitaxel-resistance (data not shown), indicating that another mechanism might be involved in the acquisition of paclitaxel-resistance in these PCa cells.

Accumulating evidence indicates that CSCs, with the abilities of tumor-initiating, self-renewal and differentiation, are responsible for the origin, progression and relapse of cancer. CSCs are thought to cause post-chemotherapeutic recurrence due to the resistance to chemotherapy by various mechanisms $(31,32)$. Thus, we examined the CSC phenotype of these DU145-TxR cells. Higher tumorigenicity is the fundamental phenotype of CSCs and can be confirmed functionally by serial xenograft transplantation of a small number of putative CSCs in immunodeficient mice $(21,33)$. Our findings demonstrated that DU145-TxR cells had higher tumorigenicity than DU145 cells by xenograft transplantation, suggesting that these DU145-TxR cells possessed potent CSC-like properties and eventually developed the paclitaxel-resistance. Therefore, further study is warranted to elucidate the potential role of CK18 in the maintenance of CSC-like properties as well as the acquisition of paclitaxelresistance in these prostate cancer cells in order to obtain more insight into the pathobiology of PCa and to develop novel therapeutics.

Moreover, the downregulation of CK18 is associated with progression of cancer and is clinically important for detecting and monitoring neoplastic disease $(26,34)$. Our data demonstrated that CK18 was downregulated in poorly differentiated (Gleason score $\geq 7$ ) PCa tissue samples, indicating a potential association of the downregulation of CK18 with tumor aggressiveness. CK18 has also been introduced as a potentially useful serum biomarker for the determination of tumor cell death of epithelial-derived tumors (carcinomas) (35). Its prime utility is in monitoring treatment and in providing early indications on recurrence and tumor progression. Encouraging data have been reported by various groups with regard to the potential use of CK18 as a clinically useful biomarker for monitoring treatment efficacy in cancer patients $(24,35,36)$. We are currently investigating the expression of CK18 in PCa tissues and serum to predict and monitor paclitaxel responsiveness. Since only $60 \%$ of CRPC patients respond to initial paclitaxelbased chemotherapy, it will be helpful to predict the paclitaxel responsiveness prior to treatment to assist in decision making for chemotherapy in these patients. It is also very important to monitor the paclitaxel responsiveness during its administration for earlier regimen adjustment and more favorable treatment outcome.

In conclusion, we demonstrated herein that the downregulation of CK18 is associated with the acquisition of paclitaxel-resistance and tumor aggressiveness in $\mathrm{PCa}$. Therefore, further study to define the potential role of CK18 
may lead to novel therapy strategies as well as a clinically useful biomarker for PCa patients.

\section{Acknowledgements}

The present study was supported by grants from the National Natural Science Foundation of China (nos. 81372725 and 81372766) and the Liaoning Provincial Natural Science Foundation (no. 2013021007).

\section{References}

1. Siegel RL, Miller KD and Jemal A: Cancer statistics, 2015. CA Cancer J Clin 65: 5-29, 2015.

2. Debes JD and Tindall DJ: Mechanisms of androgen-refractory prostate cancer. N Engl J Med 351: 1488-1490, 2004.

3. Tannock IF, de Wit R, Berry WR, Horti J, Pluzanska A, Chi KN, Oudard S, Théodore C, James ND, Turesson I, et al; TAX 327 Investigators: Docetaxel plus prednisone or mitoxantrone plus prednisone for advanced prostate cancer. N Engl J Med 351: 1502-1512, 2004.

4. Madan RA, Pal SK, Sartor O and Dahut WL: Overcoming chemotherapy resistance in prostate cancer. Clin Cancer Res 17: 3892-3902, 2011.

5. Jordan MA and Wilson L: Microtubules as a target for anticancer drugs. Nat Rev Cancer 4: 253-265, 2004.

6. Inoue T, Leman ES, Yeater DB and Getzenberg RH: The potential role of purine-rich element binding protein (PUR) alpha as a novel treatment target for hormone-refractory prostate cancer. Prostate 68: 1048-1056, 2008.

7. Zeng Y, Kulkarni P, Inoue $\mathrm{T}$ and Getzenberg RH: Downregulating cold shock protein genes impairs cancer cell survival and enhances chemosensitivity. J Cell Biochem 107: 179-188, 2009.

8. Li Y, Zeng Y, Mooney SM, Yin B, Mizokami A, Namiki M and Getzenberg RH: Resistance to paclitaxel increases the sensitivity to other microenvironmental stresses in prostate cancer cells. J Cell Biochem 112: 2125-2137, 2011.

9. Pederson T: Half a century of 'the nuclear matrix'. Mol Biol Cell 11: 799-805, 2000.

10. Getzenberg RH, Konety BR, Oeler TA, Quigley MM, Hakam A, Becich MJ and Bahnson RR: Bladder cancer-associated nuclear matrix proteins. Cancer Res 56: 1690-1694, 1996.

11. Partin AW, Getzenberg RH, CarMichael MJ, Vindivich D, Yoo J, Epstein JI and Coffey DS: Nuclear matrix protein patterns in human benign prostatic hyperplasia and prostate cancer. Cancer Res 53: 744-746, 1993.

12. Brünagel G, Vietmeier BN, Bauer AJ, Schoen RE and Getzenberg RH: Identification of nuclear matrix protein alterations associated with human colon cancer. Cancer Res 62 : 2437-2442, 2002.

13. Leman ES and Getzenberg RH: Nuclear structure as a source of cancer specific biomarkers. J Cell Biochem 104: 1988-1993, 2008.

14. Seruga B, Ocana A and Tannock IF: Drug resistance in metastatic castration-resistant prostate cancer. Nat Rev Clin Oncol 8: 12-23, 2011.

15. Kim JJ, Yin B, Christudass CS, Terada N, Rajagopalan K, Fabry B, Lee DY, Shiraishi T, Getzenberg RH, Veltri RW, et al: Acquisition of paclitaxel resistance is associated with a more aggressive and invasive phenotype in prostate cancer. J Cell Biochem 114: 1286-1293, 2013.

16. Shevchenko A, Wilm M, Vorm O and Mann M: Mass spectrometric sequencing of proteins silver-stained polyacrylamide gels. Anal Chem 68: 850-858, 1996.

17. Yin B, Zeng Y, Wang X, Liu G, Zhang M and Song Y: Expression and clinical significance of cancer-testis genes in clear cell renal cell carcinoma. Int J Clin Exp Pathol 7: 4112-4119, 2014.
18. Yin B, Liu G, Wang XS, Zhang H, Song YS and Wu B: Expression profile of cancer-testis genes in transitional cell carcinoma of the bladder. Urol Oncol 30: 886-892, 2012.

19. Mani SA, Guo W, Liao MJ, Eaton EN, Ayyanan A, Zhou AY, Brooks M, Reinhard F, Zhang CC, Shipitsin M, et al: The epithelial-mesenchymal transition generates cells with properties of stem cells. Cell 133: 704-715, 2008

20. Lonardo E, Hermann PC, Mueller MT, Huber S, Balic A, Miranda-Lorenzo I, Zagorac S, Alcala S, RodriguezArabaolaza I, Ramirez JC, et al: Nodal/Activin signaling drives self-renewal and tumorigenicity of pancreatic cancer stem cells and provides a target for combined drug therapy. Cell Stem Cell 9: 433-446, 2011

21. Visvader JE and Lindeman GJ: Cancer stem cells in solid tumours: Accumulating evidence and unresolved questions. Nat Rev Cancer 8: 755-768, 2008.

22. Schutte B, Henfling M, Kölgen W, Bouman M, Meex S, Leers MP, Nap M, Björklund V, Björklund P, Björklund B, et al: Keratin 8/18 breakdown and reorganization during apoptosis. Exp Cell Res 297: 11-26, 2004.

23. Moll R, Franke WW, Schiller DL, Geiger B and Krepler R: The catalog of human cytokeratins: Patterns of expression in normal epithelia, tumors and cultured cells. Cell 31: 11-24, 1982.

24. Linder S, Olofsson MH, Herrmann R and Ulukaya E: Utilization of cytokeratin-based biomarkers for pharmacodynamic studies. Expert Rev Mol Diagn 10: 353-359, 2010.

25. Knapp AC and Franke WW: Spontaneous losses of control of cytokeratin gene expression in transformed, non-epithelial human cells occurring at different levels of regulation. Cell 59: 67-79, 1989.

26. Woelfle U, Sauter G, Santjer S, Brakenhoff R and Pantel K: Downregulated expression of cytokeratin 18 promotes progression of human breast cancer. Clin Cancer Res 10: 2670-2674, 2004.

27. Kirfel J, Magin TM and Reichelt J: Keratins: A structural scaffold with emerging functions. Cell Mol Life Sci 60: 56-71, 2003.

28. Paramio JM and Jorcano JL: Beyond structure: Do intermediate filaments modulate cell signalling? BioEssays 24: 836-844, 2002.

29. Parekh H, Wiesen K and Simpkins H: Acquisition of taxol resistance via P-glycoprotein- and non-P-glycoprotein-mediated mechanisms in human ovarian carcinoma cells. Biochem Pharmacol 53: 461-470, 1997.

30. Liang Y, Meleady P, Cleary I, McDonnell S, Connolly L and Clynes M: Selection with melphalan or paclitaxel (Taxol) yields variants with different patterns of multidrug resistance, integrin expression and in vitro invasiveness. Eur J Cancer 37: 1041-1052, 2001.

31. Yin B, Yang Y, Zhao Z, Zeng Y, Mooney SM, Li M, Xu X, Song Y, Wu B and Yang Z: Arachidonate 12-lipoxygenase may serve as a potential marker and therapeutic target for prostate cancer stem cells. Int J Oncol 38: 1041-1046, 2011.

32. van der Horst G, Bos L and van der Pluijm G: Epithelial plasticity, cancer stem cells, and the tumor-supportive stroma in bladder carcinoma. Mol Cancer Res 10: 995-1009, 2012.

33. Yin B, Zeng Y, Liu G, Wang X, Wang P and Song Y: MAGE-A3 is highly expressed in a cancer stem cell-like side population of bladder cancer cells. Int J Clin Exp Pathol 7: 2934-2941, 2014.

34. Barak V, Goike H, Panaretakis KW and Einarsson R: Clinical utility of cytokeratins as tumor markers. Clin Biochem 37: 529-540, 2004.

35. Olofsson MH, Ueno T, Pan Y, Xu R, Cai F, van der Kuip H, Muerdter TE, Sonnenberg M, Aulitzky WE, Schwarz S, et al: Cytokeratin-18 is a useful serum biomarker for early determination of response of breast carcinomas to chemotherapy. Clin Cancer Res 13: 3198-3206, 2007.

36. Demiray M, Ulukaya EE, Arslan M, Gokgoz S, Saraydaroglu O, Ercan I, Evrensel T and Manavoglu O: Response to neoadjuvant chemotherapy in breast cancer could be predictable by measuring a novel serum apoptosis product, caspase-cleaved cytokeratin 18: A prospective pilot study. Cancer Invest 24: 669-676, 2006. 